\title{
ESTUDO DE ALGUMAS PROPRIEDADES MECÂNICAS DA MADEIRA DE UM HÍBRIDO CLONAL DE Eucalyptus urophylla X Eucalyptus grandis ${ }^{1}$
}

\author{
Fabrício Gomes Gonçalves², José Tarcísio da Silva Oliveira ${ }^{3}$, Ricardo Marius Della Lucia ${ }^{4}$ e Robert \\ Cardoso Sartório ${ }^{5}$
}

\begin{abstract}
RESUMO - A procura por madeiras oriundas de reflorestamentos destinadas à serraria é uma realidade já há muitos anos, principalmente aquelas das espécies do gênero Eucalyptus. Visando buscar novas informações importantes para esse mercado, este trabalho objetivou determinar algumas propriedades mecânicas da madeira de um híbrido clonal de Eucalyptus urophylla x Eucalyptus grandis de duas idades e provenientes de talhadia simples e de reforma. Os resultados indicaram que a madeira desse híbrido apresenta boas características tecnológicas, destacando-se a segunda tora (a partir de $3 \mathrm{~m}$ ) com as melhores propriedades de flexão estática (Módulo de Elasticidade - MOE e Módulo de Ruptura - MOR) e Compressão Axial das fibras. As árvores de maior idade (166 meses) e que sofreram dois desbastes apresentaram as melhores propriedades de flexão estática e compressão axial.
\end{abstract}

Palavras-chave: Eucalyptus urophylla x Eucalyptus grandis, módulo de ruptura e módulo de elasticidade.

\section{STUDY OF SOME MECHANICAL PROPERTIES OF WOOD IN A CLONAL HYBRID OF Eucalyptus urophylla X Eucalyptus grandis}

\begin{abstract}
The search for wood originated from reforestations destined to sawmill has been observed for many years, mainly for the Eucalyptus species. Searching for information to assist this market, the aim of this study was to determine some mechanical properties of the wood from a Eucalyptus urophylla $x$ Eucalyptus grandis clonal hybrid, at two different ages and coming from coppice and reform. The results show that the wood of this clonal hybrid presents good technological characteristics and is the second best log (starting from 3, $0 \mathrm{~m}$ ), as to static bending properties (Module of Elasticity-MOE and Module of Rupture - MOR). The oldest trees (166 months -E2) which suffered two thinning presented the best results for the property of static bending and axial crushing (CA).
\end{abstract}

Keywords: Eucalyptus urophylla $x$ Eucalyptus grandis, module of rupture and module of elasticity.

\section{INTRODUÇÃO}

Uma intensificação no uso da madeira como matériaprima para fins industriais ou construtivos só pode ocorrer a partir do conhecimento adequado de suas propriedades, sejam elas físicas ou mecânicas. A madeira, por ser elemento orgânico, heterogêneo e composto basicamente de celulose, hemicelulose, lignina e extrativos, apresenta enorme versatilidade de usos para obtenção de uma série de produtos.

As propriedades mecânicas da madeira são influenciadas por diversos fatores, sendo os mais importantes a posição na árvore, a umidade, o tempo de duração da carga e a estrutura da madeira (PFEIL e PFEIL, 2003). Evans et al. (2000) apud Lobão et al.

\footnotetext{
${ }^{1}$ Recebido em 20.02.2007 e aceito para publicação em 06.03.2009.

${ }^{2}$ InstitutoFederal deEducação, Ciênciae Tecnologia deMinas Gerais-Campus SaoJoaoEvangelista-IFMG-SJE.E-mail:<fabricio@agronet.gov.br> .

${ }^{3}$ Departamento de Engenharia Florestal da Universidade Federal do Espírito Santo (UFES). E-mail: <jtsilva@ npd.ufes.br>.

${ }^{4}$ Departamento de Engenharia Florestal da Universidade Federal de Viçosa (UFV). E-mail: <rdlucia@ufv.br>.

${ }^{5}$ Aracruz Celulose S.A., Aracruz-ES.
} 
(2004) mencionam que as propriedades mecânicas da madeira são dependentes, principalmente, da densidade básica, da porcentagem de madeira juvenil, da intensidade ao ataque de insetos e da presença de nós. Green et al. (1999) citaram que essas propriedades mecânicas são afetadas pelas mudanças no teor de umidade abaixo do ponto de saturação das fibras, diminuindo com o aumento desse teor.

Entre as propriedades físicas, a que se destaca como de fundamental importância para a produção tecnológica e utilização da madeira é a densidade básica, que muitas vezes está correlacionada a outras propriedades. Lobão et al. (2004), por exemplo, afirmaram que a densidade influencia diretamente a resistência mecânica da madeira. Panshin e De Zeeuw (1964) mencionaram que a densidade básica, de forma geral, aumenta com a idade e de forma mais rápida durante a fase juvenil e que as propriedades mecânicas podem ser alteradas pela presença de extrativos, o que pode aumentar a resistência à compressão axial da madeira.

Com relação às espécies de eucalipto, a madeira na maioria delas possui enorme potencial do ponto de vista de fornecimento de matéria-prima para os diferentes setores madeireiros. Oliveira (1997) citou que o gênero Eucalyptus não apresenta restrições quanto à resistência mecânica que pode variar de baixa a muito elevada. Essa grande variabilidade se deve ao fato da existência de mais de 600 espécies, adaptadas aos mais diferentes tipos de solo e condições climáticas. O módulo de ruptura (MOR) e o módulo de elasticidade (MOE) são dois parâmetros normalmente avaliados em testes de flexão estática, sendo o módulo de elasticidade de maior importância na caracterização tecnológica da madeira, pois representa a resistência do material submetido a uma força aplicada perpendicularmente ao eixo longitudinal da madeira (SCANAVACA JÚNIOR e GARCIA, 2004).

Gonçalves et al. (2004) realizaram vasta revisão bibliográfica sobre os efeitos de tratos silviculturais (adubação, espaçamento, controle de ervas daninhas e desbastes) na produtividade e qualidade da madeira em plantações de eucalipto. Concluíram que não há regra específica para explicar o efeito de diferentes tratamentos silviculturais na densidade da madeira, por exemplo. Afirmaram que fatores ambientais, como disponibilidade de luz, pluviosidade e temperatura, causam efeitos mais significativos na composição da madeira.

R. Árvore, Viçosa-MG, v.33, n.3, p.501-509, 2009
Haselein et al. (2002), estudando o efeito do espaçamento e da adubação nas propriedades de flexão estática em madeira verde e seca de Eucalyptus saligna de 10 anos de idade, constataram efeitos significativos sobre o módulo de elasticidade e o módulo de ruptura. Concluíram que, quanto maior a dose de adubação e espaçamento, maiores os valores absolutos das propriedades.

A idade também pode proporcionar alterações nas propriedades mecânicas da madeira. Pearson e Gilmore (1980), estudando diferentes taxas de crescimento em Pinus taeda com idades de 15, 25 e 41 anos em sistemas silviculturais diferenciados, afirmaram que em árvores mais jovens as propriedades mecânicas são geralmente menores.

As propriedades da madeira de eucalipto, de acordo com Cruz et al. (2003), apresentam variações nos sentidos radial e longitudinal de seu crescimento. Esses autores, estudando a variação das propriedades físicas e mecânicas da madeira de híbridos de Eucalyptus urophylla e Eucalyptus camaldulensis com idades de 5,5 e 10,5 anos, relataram que, em ambas as propriedades, as maiores variações encontradas estavam localizadas na direção medula-casca, não havendo variações muito expressivas na direção da base para o topo das árvores.

Moura (2000) apud Cruz et al. (2003), avaliando a flexão estática e a compressão paralela entre toras de 10 clones de híbridos de eucalipto, verificaram a existência de diferenças estatísticas entre eles, sendo, de modo geral, os maiores valores encontrados nas toras superiores.

Assim, este trabalho teve por objetivo avaliar algumas propriedades mecânicas, como a rigidez e resistência à flexão estática (avaliadas, respectivamente, pelo módulo de elasticidade - MOE e pelo módulo de ruptura - MOR) e a resistência à compressão axial nas primeiras duas toras de um híbrido clonal de Eucalyptus urophylla x Eucalyptus grandis em duas diferentes idades e provenientes de talhadia simples e de reforma. Objetivou-se, ainda, a avaliação da variação radial nas toras com relação a todas as propriedades anteriormente mencionadas.

\section{MATERIAL E MÉTODOS}

A madeira deste estudo foi coletada em um experimento com clones de propriedade da empresa 
Aracruz Celulose S.A., localizada no Sul do Estado da Bahia, Municípios de Mucuri e Nova Viçosa.

O solo local é pertencente à Formação Barreiras, sendo predominante nos três extratos estudados o Podzólico Amarelo Distrófico e apresenta relevo de suave a plano. De acordo com a classificação climática de Köppen, há predomínio do tipo “Af”, sendo clima tropical chuvoso e quente, com temperatura superior a $18{ }^{\circ} \mathrm{C}$ no mês mais frio. A precipitação anual está em torno de 1.378,0 mm, e no mês mais seco ocorre precipitação em torno de $60,0 \mathrm{~mm}$. A região Sul do Estado da Bahia apresenta déficit hídrico em torno de 124,0 mm e um excedente anual próximo de 78,0 mm (com base em séries históricas de apenas 10 anos).

Foram abatidas 15 árvores de um clone das espécies Eucalyptus urophylla $\mathrm{x}$ Eucalyptus grandis, com diâmetros entre 28,0 e 30,0 cm à altura do peito (DAP). Os dados foram analisados através da estatística descritiva e da análise de regressão. Isso foi necessário, uma vez que o material disponibilizado para o estudo não permitiu adequada padronização entre os extratos.

Foi utilizado apenas o modelo linear, quando significativo, no ajustamento da equação aos dados observados, tendo em vista o pequeno número de posições radiais disponíveis no nível de significância de 5\%. A Tabela 1 apresenta, de forma resumida, as características gerais dos extratos avaliados neste estudo.

De cada árvore foi retirada duas primeiras toras com $3 \mathrm{~m}$ de comprimento, visando à confecção dos corpos-de-prova. Uma peça central, incluindo a medula, com espessura aproximada de $5,0 \mathrm{~cm}$, foi retirada de cada tora. As toras foram seccionadas em seu comprimento em duas partes iguais, sendo obtidos corpos-de-prova verdes de $50 \%$ destas e o restante colocados para secar à sombra, em local coberto, até atingir a umidade de equilíbrio. Foram confeccionados corpos-de-prova com dimensões de 2,0 x 2,0 x 30,0 cm, para a realização dos testes de flexão estática (Módulo de Ruptura - MOR e Módulo de Elasticidade - MOE); e corpos-de-prova com dimensões de 2,0 x 2,0 x 3,0 $\mathrm{cm}$, para o teste de resistência à Compressão Axial (Norma MB-26/40-ABNT). Foram obtidos corpos-deprova na direção medula-casca, com quatro repetições por posição por tora. A Tabela 2 apresenta o número de corpos-de-prova confeccionados para cada ensaio.

Tabela 1 - Características gerais dos extratos estudados Table 1 -General characteristics in the studied extract

\begin{tabular}{|c|c|c|c|}
\hline \multirow[t]{2}{*}{ Características } & \multicolumn{3}{|c|}{ Extratos } \\
\hline & E1 & $\mathrm{E} 2$ & E3 \\
\hline Época de plantio & $03 / 1999$ & $03 / 1991$ & $06 / 1999$ \\
\hline Condução de plantio & Talhadia & Reforma & Reforma \\
\hline Espaçamento (m) & $3,0 \times 3,0$ & $3,0 \times 3,0$ & $6,0 \times 2,5$ \\
\hline Capina química (unidade) & 04 & 07 & 01 \\
\hline Roçada manual (unidade) & 04 & 04 & 04 \\
\hline Idade de corte (meses) & 70 & 166 & 70 \\
\hline Desbaste (meses) & 30 & 117 e 153 & 42 \\
\hline $\mathrm{N}^{\circ}$ de cepas (a partir de 9 meses) & 01 & 01 & 01 \\
\hline Volume de madeira/ha $\left(\mathrm{m}^{3}\right)$ & 169,01 & 364,07 & 119,27 \\
\hline Densidade na época do corte (árv/ha) & 150 & 325 & 150 \\
\hline
\end{tabular}

Tabela 2 - Número de corpos-de-prova confeccionados para realização dos ensaios mecânicos na madeira do clone de Eucalyptus urophylla x Eucalyptus grandis

Table 2 - Number of samples used in the mechanical analysis in the wood in a clonal hybrid of Eucalyptus urophylla $x$ Eucalyptus grandis

\begin{tabular}{|c|c|c|c|c|c|c|c|}
\hline \multirow[t]{2}{*}{ Ensaios } & \multirow[t]{2}{*}{$\begin{array}{l}\text { Condição } \\
\text { Umidade }\end{array}$} & \multicolumn{2}{|c|}{$\begin{array}{c}\text { E1 - Talhadia } \\
(70 \text { meses })\end{array}$} & \multicolumn{2}{|c|}{$\begin{array}{c}\text { E2 - Reforma } \\
(166 \text { meses })\end{array}$} & \multicolumn{2}{|c|}{$\begin{array}{c}\text { E3 - Reforma } \\
(70 \text { meses })\end{array}$} \\
\hline & & Tora 1 & Tora 2 & Tora 1 & Tora 2 & Tora 1 & Tora 2 \\
\hline \multirow[t]{2}{*}{ Flexão estática (MOR e MOE) } & Verde & 65 & 66 & 80 & 50 & 74 & 54 \\
\hline & Seca & 66 & 68 & 71 & 58 & 53 & 63 \\
\hline \multirow[t]{2}{*}{ Compressão axial } & Verde & 69 & 65 & 82 & 72 & 82 & 58 \\
\hline & Seca & 72 & 68 & 76 & 60 & 56 & 64 \\
\hline
\end{tabular}


Os ensaios mecânicos foram realizados em uma máquina universal de ensaios com sistema de aquisição de dados automatizado, instalada no Laboratório de Ciência da Madeira - LCM, do Núcleo de Estudos e de Difusão de Tecnologia em Floresta, Recursos Hídricos e Agricultura Sustentável - NEDTEC, do Centro de Ciências Agrárias da Universidade Federal do Espírito Santo, localizado no município de Jerônimo Monteiro, ES (Figura 1).

Após os ensaios de flexão estática e resistência à compressão, foram retiradas pequenas amostras para determinação do teor de umidade no momento do ensaio. Posteriormente, as resistências obtidas foram corrigidas para $12 \%$, conforme a NBR 7190 (ABNT, 1997), pela equação 1 .

$$
f_{12 \%}=f_{U \%}\left(1+\left(\frac{2(U \%-12)}{100}\right)\right)
$$

em que:

$f_{12 \%}=$ valor da resistência no teor de $12 \%$ de umidade;

$f_{U \%}=$ valor da resistência encontrado no teor de umidade ensaiado; e

$U \%=$ umidade do corpo-de-prova no momento do ensaio.

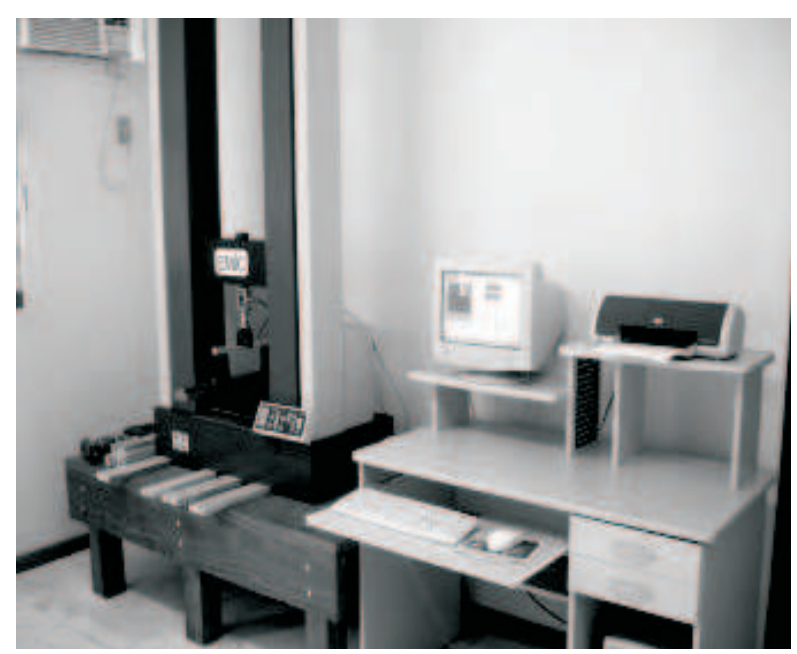

Figura 1 - Máquina universal de ensaios com tomada automática de dados.

Figure 1-Equipment for the automatic obtainment of data.

\section{RESULTADOS E DISCUSSÃO}

O teor de umidade médio, corrigido para o teor de umidade de $12 \%$, encontrado no momento dos testes de flexão estática e resistência à compressão axial foi de $16,7 \%$ (Tabela 3 ).

O módulo de ruptura (MOR), forma convencional de avaliação da resistência à flexão, importante responsável por conferir a capacidade de carregamento em peças estruturais na forma de vigas, comportouse de forma satisfatória, destacando-se a segunda tora com os maiores valores absolutos nos extratos E1 e E3, ambos com mesma idade. É importante salientar que, de forma geral, os coeficientes de variação foram maiores no segundo extrato, demonstrando maior heterogeneidade entre as amostras avaliadas. O desempenho do extrato E3, mesmo apresentando maior espaçamento e com desbaste realizado aos 42 meses, foi muito próximo em relação primeiro extrato conduzido sob talhadia simples e com desbaste realizado precocemente, o que pode indicar que o espaçamento e o desbaste contribuíram pouco para alterar essa propriedade mecânica.

No ensaio realizado neste estudo, as mesmas observações feitas para o MOR podem ser aqui aplicadas ao MOE. No entanto, as amostras demonstraram maior heterogeneidade no extrato $\mathrm{E} 3$ em relação ao $\mathrm{E} 1$, conforme observado nos coeficientes de variação (Tabela 3 ). Esse fato pode estar associado ao rápido crescimento em diâmetro das árvores, proporcionado pelo desbaste na época certa em conjunto com o maior espaçamento de plantio $(6,0 \times 2,5 \mathrm{~m})$.

O conhecimento da resistência à compressão axial é importante quando se utiliza a madeira para colunas e treliças. Neste estudo, a madeira do híbrido clonal de Eucalyptus urophylla x Eucalyptus grandis apresentou os melhores resultados em termos absolutos para a tora 2 nos extratos E1 e E3. Os resultados dos ensaios de compressão axial indicaram que, entre os extratos, árvores de maior idade cultivadas com a realização de dois desbastes tardios (E2) apresentamse mais resistentes. Salienta-se que os maiores coeficientes de variação da resistência à compressão axial estão no extrato E2. Nos extratos E1 e E3, os coeficientes de variação são menores, indicando haver menor variabilidade na madeira, o que a torna de melhor qualidade em relação a essa propriedade. 
Tabela 3 - Valores médios da flexão estática (Módulo de Ruptura - MOR e Módulo de Elasticidade - MOE), resistência à Compressão Axial (CA) e densidade básica da madeira seca (corrigida para 12\%) e verde do híbrido clonal de Eucalyptus urophylla $\mathrm{x}$ Eucalyptus grandis

Table 3 -Average values for Module of Rupture, Module of Elasticity, Axial Crushing and specific gravity for the dry wood (12\% of moistness) and green wood in a clonal hybrid of Eucalyptus urophylla x Eucalyptus grandis

\begin{tabular}{|c|c|c|c|c|}
\hline \multirow[t]{3}{*}{ Propriedades } & \multirow[t]{3}{*}{ Toras } & \multicolumn{3}{|c|}{ Extratos } \\
\hline & & E1 - Talhadia (70 meses) & E2 - Reforma (166 meses) & E3 - Reforma (70 meses) \\
\hline & & \multicolumn{3}{|c|}{ Madeira Seca } \\
\hline \multirow[t]{2}{*}{ MOR (MPa) } & 1 & $82,95(9,27)$ & $103,2(20,56)$ & $83,21 \quad(12,72)$ \\
\hline & 2 & $89,47(9,03)$ & $101,4(22,97)$ & $91,70(12,64)$ \\
\hline \multirow[t]{2}{*}{ MOE (MPa) } & 1 & $9.798(11,73)$ & $12.474(18,26)$ & $9.652(14,68)$ \\
\hline & 2 & $10.883(8,84)$ & $12.781(18,72)$ & $10.900(12,38)$ \\
\hline \multirow[t]{2}{*}{$\mathrm{CA}(\mathrm{MPa})$} & 1 & $49,80(7,79)$ & $67,38(13,19)$ & $51,17(13,93)$ \\
\hline & 2 & $53,96(7,52)$ & $67,08(15,17)$ & $55,17(8,52)$ \\
\hline \multirow[t]{3}{*}{ Densidade $\left(\mathrm{g} / \mathrm{cm}^{3}\right)$} & 1 & $0,45(7,34)$ & $0,53(17,12)$ & $0,49(7,09)$ \\
\hline & 2 & $0,49(4,83)$ & $0,56(12,23)$ & $0,49(13,48)$ \\
\hline & & \multicolumn{3}{|c|}{ Madeira Verde } \\
\hline \multirow[t]{2}{*}{ MOR (MPa) } & 1 & $64,60(10,38)$ & $70,00(24,13)$ & $68,00(12,04)$ \\
\hline & 2 & $70,90(8,73)$ & $68,20(21,43)$ & $72,80(9,46)$ \\
\hline \multirow[t]{2}{*}{ MOE (MPa) } & 1 & $8.172(12,38)$ & $9.874(26,00)$ & $8.490(16,54)$ \\
\hline & 2 & $9.396(10,08)$ & $9.964(22,82)$ & $9.526(10,79)$ \\
\hline \multirow[t]{2}{*}{$\mathrm{CA}(\mathrm{MPa})$} & 1 & $33,70(8,52)$ & $36,10(19,47)$ & $35,60(10,62)$ \\
\hline & 2 & $37,60(5,77)$ & $39,70(13,70)$ & $37,30(9,72)$ \\
\hline
\end{tabular}

* Valor entre parênteses abaixo do ponto médio indica Coeficiente de Variação (\%).

A Tabela 3 apresenta os resultados médios dos ensaios de flexão (módulo de elasticidade - MOE e módulo de ruptura - MOR) e resistência à Compressão Axial da madeira nas condições seca e verde.

Haselein et al. (2002) citaram que abaixo do ponto de saturação das fibras há diminuição na resistência mecânica com o aumento do teor de umidade. Este trabalho confirma essa hipótese quando se confrontam com os dados expressos na Tabela 3. Esses autores também encontraram valores inferiores de resistência mecânica para madeiras verde de Eucalyptus saligna de 10 anos de idade.

Os valores encontrados neste estudo, no que se refere aos módulos de elasticidade e ruptura, estão próximos daqueles mencionados por Bodig e Jayne (1982) apud Haselein et al. (2002). Afirmaram que, em madeiras de folhosas, a razão da madeira seca (12\% de umidade) para a madeira verde varia de 1,11 a 1,53 para MOE e de 1,32 a 2,10 para MOR.

Cruz et al. (2003), analisando as dimensões dos componentes anatômicos da madeira presentes na segunda tora, objeto também deste estudo, afirmaram que podem contribuir para aumento das propriedades mecânicas. De fato, neste estudo os maiores valores absolutos estavam presentes na segunda tora, à exceção do extrato E2, em árvores com maior idade. Esses mesmos autores, avaliando as variações das propriedades dentro das árvores e entre clones de híbridos de eucalipto, encontraram para a compressão paralela um valor médio igual a 46,6 MPa, inferior ao observado neste trabalho.

A Figura 2 ilustra, graficamente, o comportamento médio do módulo de ruptura (MOR) na direção medulacasca, corrigidos para $12 \%$ de umidade, com as respectivas equações ajustadas aos três extratos estudados.

As equações ajustadas indicam tendência de aumento linear crescente do módulo de ruptura da medula para a periferia do tronco (Figura 2). Destaca-se a segunda tora do primeiro extrato, com maiores valores absolutos. De modo geral, o modelo linear aponta para a madeira adulta como a mais resistente. Nas demais toras, a regressão foi não significativa. Serpa et al. (2003), estudando a madeira de Eucalyptus saligna (40 anos) e E. grandis (50 anos), encontraram valores crescentes da flexão estática na direção medula-casca. Esses autores ainda afirmaram que a maior resistência na direção do alburno se deve ao fato de a madeira juvenil ser menos resistente.

R. Árvore, Viçosa-MG, v.33, n.3, p.501-509, 2009 
De acordo com Panshin e De Zeeuw (1964), a resistência da madeira está associada à sua densidade, o que pode explicar as maiores resistências, em termos absolutos, encontradas no segundo extrato (Tabela 3 ).

A Figura 3 ilustra, graficamente, o comportamento médio do módulo de elasticidade (MOE) na direção medula-casca, corrigidos para $12 \%$ de umidade com as respectivas equações ajustadas aos três extratos estudados.

Neste trabalho, o módulo de elasticidade apresentou tendência de crescimento na direção medula-casca na primeira tora dos extratos E1 e E3. As equações ajustadas (Figura 3) indicam que a madeira adulta é capaz de suportar maior carga e retornar ao mais próximo de sua condição original (anterior à aplicação da carga).
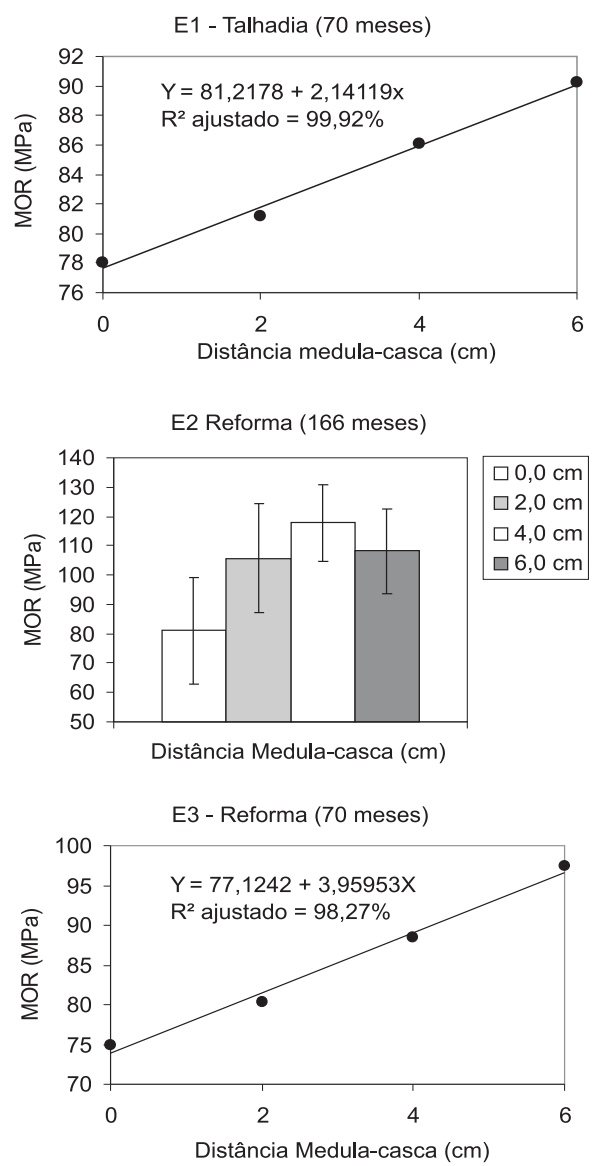

(A)
Destaca-se a primeira tora do extrato E1 com maiores valores mais próximos à medula, o que pode ser considerado vantagem quanto ao maior aproveitamento da tora. Nas demais toras, a regressão foi não significativa. Resultados expressivos na variação das propriedades mecânicas na direção medula-casca das madeiras de eucalipto também foram encontrados por Cruz et al. (2003).

Balarin e Nogueira (2003) promoveram caracterização elástica na madeira de Corymbia citriodora com 65 anos de idade. Encontraram para o módulo de elasticidade na direção longitudinal valor igual a $16.580 \mathrm{Mpa}$, calculado por meio de ensaio de tração, valor esse muito superior ao verificado neste estudo em qualquer um dos três extratos avaliados.
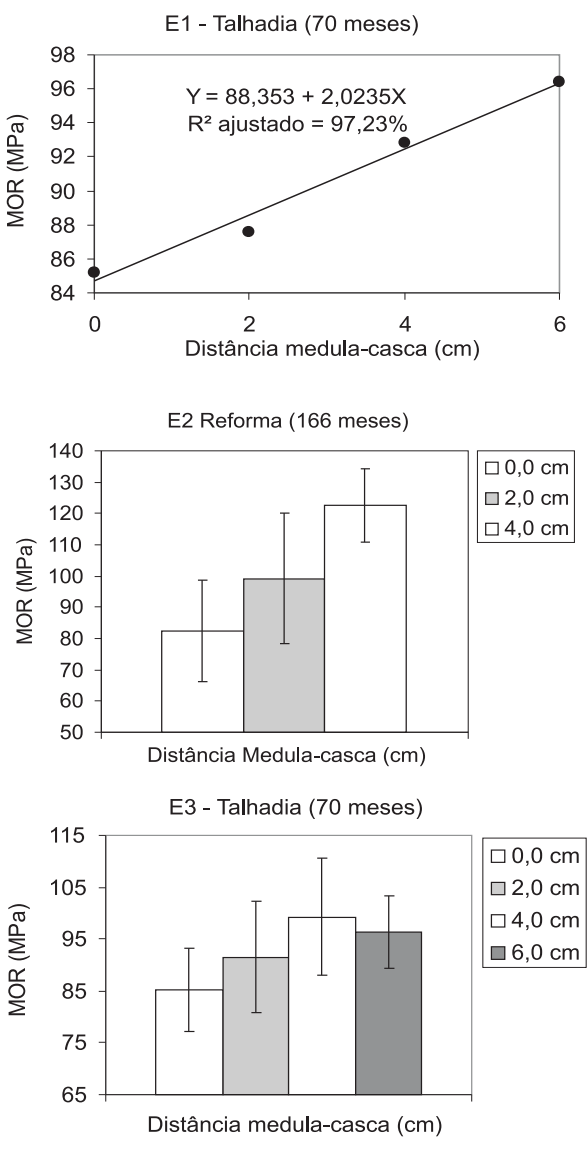

(B)

Figura 2 - Representação gráfica do Módulo de Ruptura (MOR) médio na direção medula-casca a 12\% de umidade da primeira tora (A) e segunda tora (B) do híbrido clonal de Eucalyptus urophylla x eucalyptus grandis.

Figure 2 - Graphic representation of the average Module of Rupture (MOR) in the pith-bark direction at $12 \%$ of moistness for the first $\log (A)$ and second $\log (B)$ in a clonal hybrid of Eucalyptus urophylla $x$ Eucalyptus grandis.

R. Árvore, Viçosa-MG, v.33, n.3, p.501-509, 2009 
Silva (2002), caracterizando a madeira de Eucalyptus grandis com idades de 120, 168, 240 e 300 meses, encontrou valor médio para o módulo de elasticidade de 10.131,3 Мpa, 13.592,6 Мpa, 14.912 Mpa e 13.055,9 Mpa, respectivamente. Neste estudo, o segundo extrato, com 166 meses, apresentou valores inferiores ao encontrado por aquele autor para a mesma idade em ambas as toras.

A Figura 4 ilustra, graficamente, o comportamento médio da resistência à compressão axial (CA) na direção medula-casca, corrigidos para $12 \%$ de umidade, com a respectiva equação ajustada aos três extratos estudados. Verifica-se, nessa figura, que apenas a primeira tora do terceiro extrato apresentou tendência linear crescente e significativa a $5 \%$ de probabilidade. Nas demais toras, não foi possível estimar uma equação, tendo em vista a regressão não ser significativa. Observase, ainda na Ffigura 4, a variação dos desvios- padrão nas diferentes posições nos extratos. As posições mais afastadas da medula, de forma geral, apresentam-se na referida figura, mais próximas da média indicando menores variações na madeira.
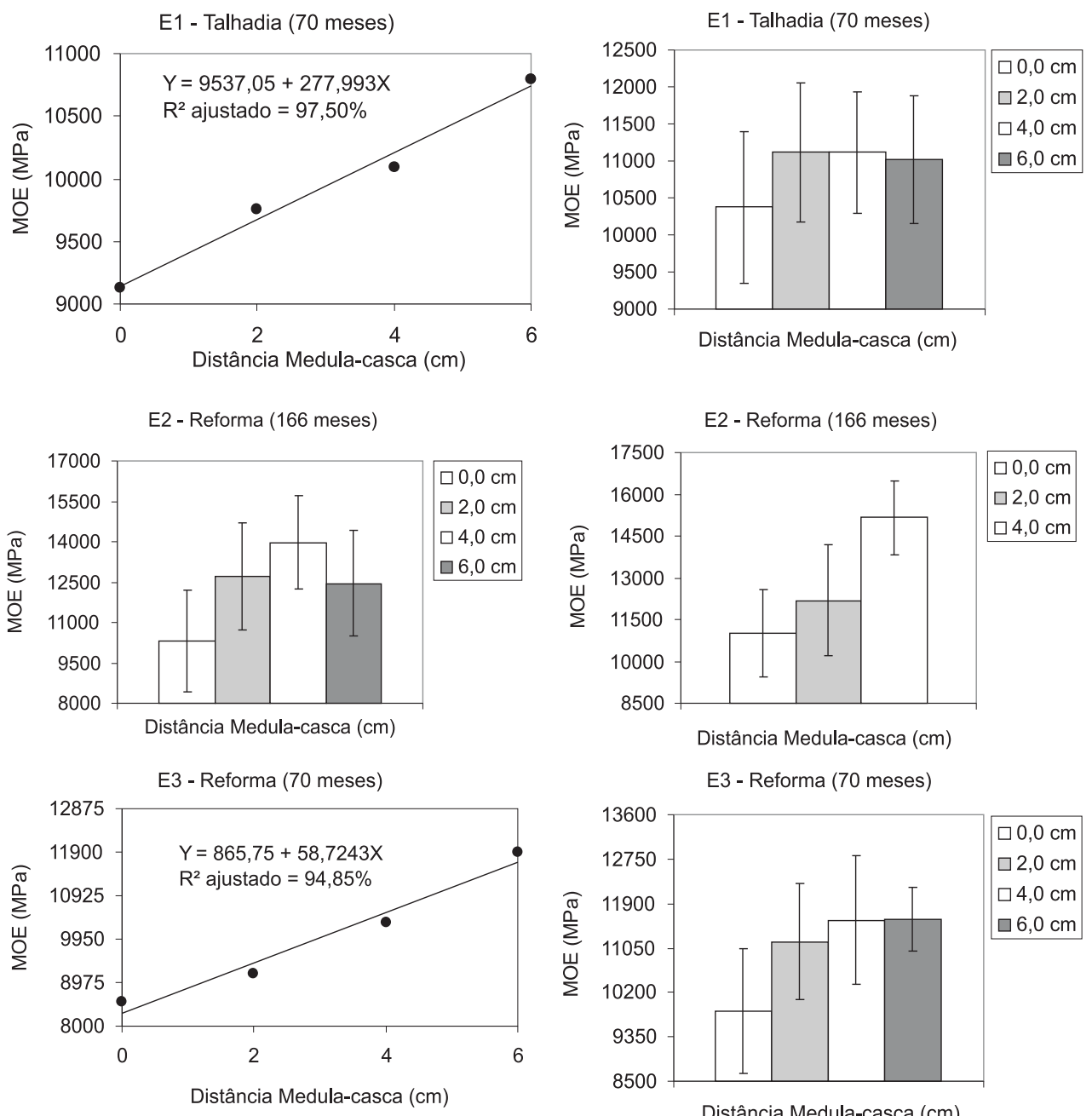

(A)

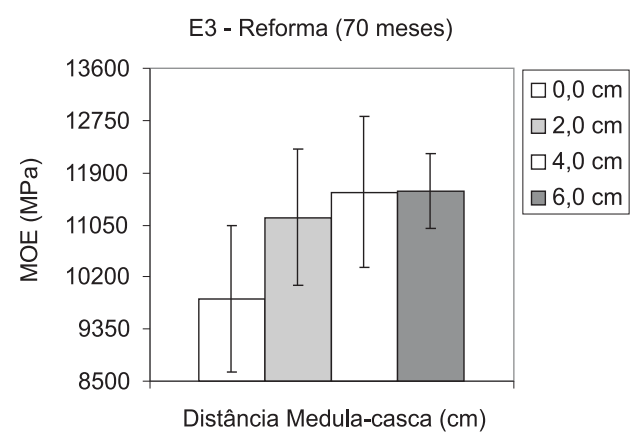

(B)

Figura 3 - Representação gráfica do Módulo de Elasticidade (MOE) médio na direção medula-casca a 12\% de umidade da primeira tora (A) e segunda tora (B) do híbrido clonal de Eucalyptus urophylla x Eucalyptus grandis.

Figure 3 - Graphic representation of the average Module of Elasticity (MOE) in the pith-bark direction at $12 \%$ of moistness for the first $\log (A)$ and second $\log (B)$ in a clonal hybrid of Eucalyptus urophylla $x$ Eucalyptus grandis. 

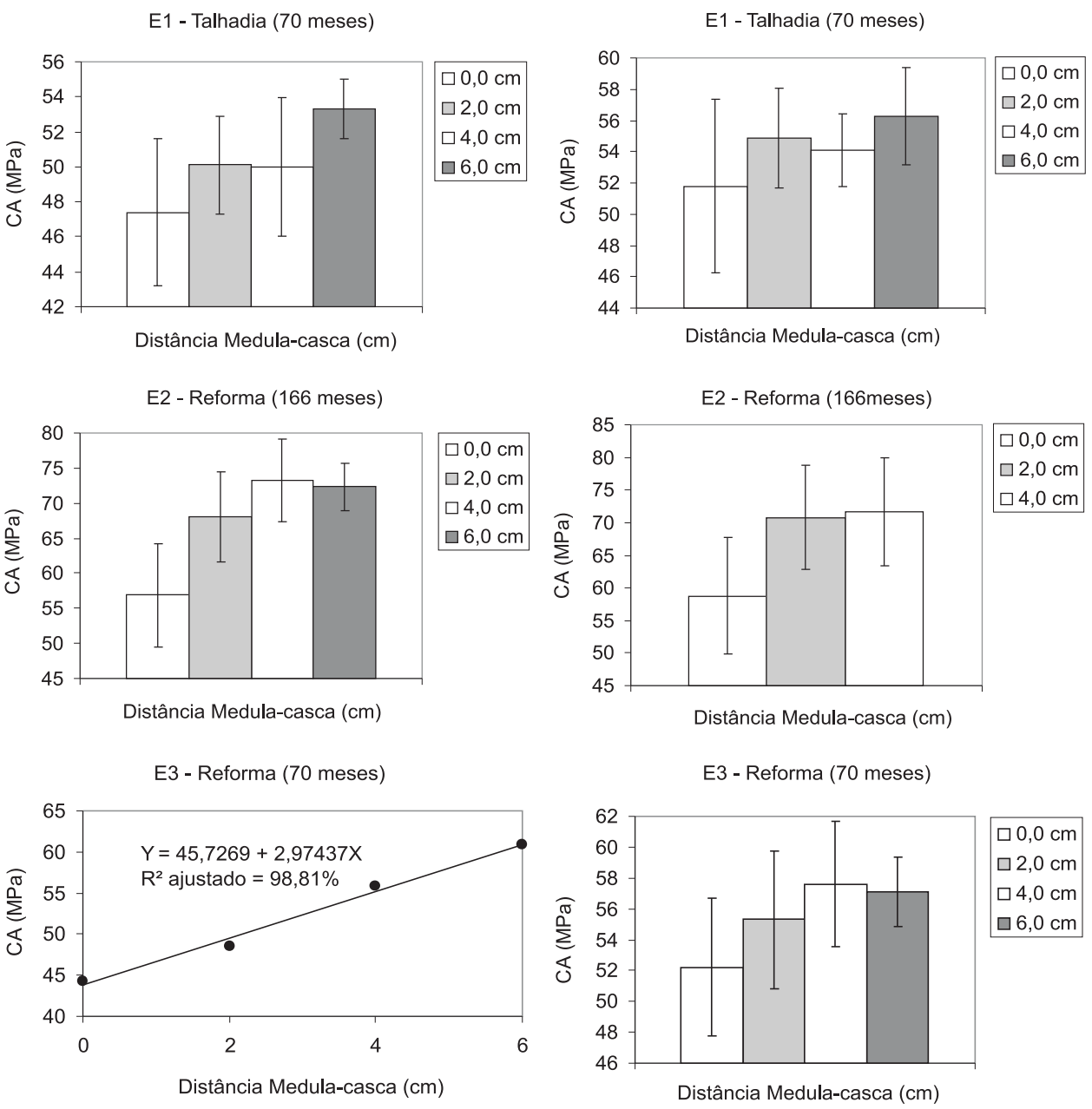

(A)

(B)

Figura 4 - Representação gráfica da resistência à Compressão Axial (CA) média na direção medula-casca a $12 \%$ de umidade da primeira tora (A) e segunda tora (B) do híbrido clonal de Eucalyptus urophylla x Eucalyptus grandis.

Figure 4-Graphic representation of the average resistance to the Axial Crushing (CA) in the pith-bark direction at $12 \%$ of moistness for the first $\log (A)$ and second $\log (B)$ in a clonal hybrid of Eucalyptus urophylla $x$ Eucalyptus grandis.

\section{CONCLUSÕES}

Com base nos resultados, nas considerações e nas condições em que foram realizados os ensaios, são apresentadas as seguintes conclusões:

- A segunda tora apresentou os maiores valores absolutos em todos os extratos avaliados com relação a todas as propriedades mecânicas, indicando melhores propriedades mecânicas.

- Os extratos E1 e E3 apresentaram comportamento parecido entre as toras em todas as propriedades avaliadas;

- O espaçamento e os desbastes, aparentemente, não influenciaram as propriedades de flexão estática (MOR e MOE) nos extratos de mesma idade (E1 e E3), apesar de o extrato E3 apresentar valores absolutos pouco superiores e com maior variabilidade nas amostras.

- As propriedades que permitiram ajuste de equação aos dados observados apresentaram bom coeficiente de correlação, indicando a boa confiabilidade na estimativa das propriedades avaliadas.

R. Árvore, Viçosa-MG, v.33, n.3, p.501-509, 2009 


\section{REFERÊNCIAS}

ASSOCIAÇÃO BRASILEIRA DE NORMAS TÉCNICAS - ABNT. Ensaios físicos e mecânicos da madeira. MB-26/40. Rio de Janeiro: 1940. 16p.

\section{ASSOCIAÇÃO BRASILEIRA DE NORMAS} TÉCNICAS - ABNT. Projeto de estruturas de madeira - NBR 7190. Rio de Janeiro: 1997. 107p.

BALARIN, A. W.; NOGUEIRA, M. Caracterização elástica da madeira de Eucalyptus citriodora. Revista Cerne, v.9, n.1, p.66-80, 2003.

CRUZ, C. R.; LIMA, J. T.; MUNIZ, G. I. B. Variações dentro das árvores e entre clones das propriedades físicas e mecânicas da madeira de híbridos de Eucalyptus. Revista Scientia Forestalis, n.64, p.33-47, 2003.

GONÇALVES, J. L. M. et al. Silvicultural effects on the productivity and wood quality of eucalypt plantation. Forest Ecology and Management, v.192, n.1, p.45-61, 2004.

GREEN, D.; WINANDY, J. E.; KRETSCHMANN, D. E. Mechanical properties of wood. In: Wood handbook - Wood as an engineering material. Madison: U.S. Department of Agriculture, Forest Products Laboratory, 1999. Chapter 4.

HASELEIN, C. R. et al. Propriedades de flexão estática da madeira úmida e a $12 \%$ de umidade de um clone de Eucalyptus saligna Smith sob o efeito do espaçamento e da adubação.

Revista Ciência Florestal, v.12, n.2, p.147-152, 2002.
LOBÃO, M. S. et al. Caracterização das propriedades físico-mecânicas da madeira de eucalipto com diferentes densidades. Revista Árvore, v.28, n.6, p.889-894, 2004.

OLIVEIRA, J. T. S. Caracterização da madeira de eucalipto para a construção civil. 1997. 429f. Tese (Doutorado em Engenharia Civil) - Escola Politécnica da Universidade de São Paulo, São Paulo, 1997.

PANSHIN, A. J.; DE ZEEUW, C. Textbook of wood tecnology. 2.ed. New York: McGraw Hill, 1964. v.1.643p.

PEARSON, R. G.; GILMORE, R. C. Effect of fast growth rate on the mechanical properties of loblolly pine. Forest Products Journal, v.30, n.5, p.47-54, 1980.

PFEIL, W.; PFEIL, M. Estruturas de madeira. 6.ed. Rio de Janeiro: LTC, 2003. 224p.

SCANAVACA JÚNIOR, L.; GARCIA, J. N.

Determinação das propriedades físicas e mecânicas da madeira de Eucalyptus urophylla. Scientia Forestalis, v.65, p.120-129, 2004.

SERPA, P. N. et al. Avaliação de algumas propriedades da madeira de Eucalyptus grandis, Eucalyptus saligna e Pinus elliottii. Revista Árvore, v.27, n.5, p.723-733, 2003.

SILVA, J. C. Caracterização da madeira de Eucalyptus grandis Hill ex. Maiden, de diferentes idades, visando a sua utilização na indústria moveleira. 2002. 160f. Tese (Doutorado em Ciências Florestais) Universidade Federal do Paraná, Curitiba, 2002. 
